DOI: $10.14451 / 1.202 .171$

\title{
ОРГАНИЗАЦИОННО-ЭКОНОМИЧЕСКИЕ ОСНОВЫ УСИЛЕНИЯ ОНКОЛОГИЧЕСКОЙ СЛУЖБЫ В РОССИИ
}

\author{
(c) 2021 Сибилёв Дмитрий Владимирович \\ аспирант ИГСУ РАНХиГС \\ Институт Государственной Службы и Управления и Управления \\ Российская Академия Народного Хозяйства и Государственной Службы при Президенте РФ \\ (РАНХиГС), Россия, Москва \\ Email: sdmitry2002@gmail.com \\ (C) 2021 Панова Татьяна Владимировна \\ кандидат экономических наук \\ декан факультета Международного регионоведения и регионального управления \\ Институт Государственной Службы и Управления и Управления \\ Российская Академия Народного Хозяйства и Государственной Службы при Президенте РФ \\ (РАНХиГС), Россия, Москва \\ Email: tv.panova@igsu.ru
}

Лечение онкологических заболеваний является актуальной проблемой здравоохранения не только России, но и всего мира. Приоритетная программа развития здравоохранения направлена на повышение ранней диагностики и снижение смертности от онкологических заболеваний, в связи с чем финансированию онкологической службы уделяется особое внимание.

Ключевые слова: опухоли, диагностика, смертность, финансирование, затраты, нацпроект.

Интерес к изучению финансирования и развития онкологической службы на территории России связан с тем, что онкологические заболевания широко распространены среди населения, характеризуются высокой смертностью, а также большими экономическими затратами.

Нацпроект «Здравоохранение» направлен на снижение смертности населения трудоспособного возраста от заболеваний, среди которых онкологические заболевания по смертности занимают второе место в стране. На реализацию нацпроекта в РФ в 2019-2024 гг. выделено более 1,7 трлн. рублей. В нацпроект входит федеральный проект «Борьба с онкологическими заболеваниями», направленный на снижение смертности от онкологических заболеваний до 185 случаев на 100 тысяч человек к 2024 г. [1].

В рамках проекта решаются вопросы обеспечения специалистами лечебно-диагностических центров, переоснащение амбулаторно-поликлинической службы, а также создание дополнительных центров для диагностики и лечения опухолевых заболеваний. Для реализации данного направления в период 2019-2024 гг. выделено 969 млрд. рублей, что составляет 63\% бюджета национального проекта.

Из Федерального Фонда ОМС на оплату ме- дицинской помощи онкологическим больным в 2020 г. направлено 271,3 млрд. рублей. Из них на хирургическое лечение выделено 9,4 млрд. рублей. 10,6 млрд. рублей на конформную лучевую терапию и еще 5 млрд. рублей на протонную терапию, вошедшую в список высокотехнологичных методов лечения, не включенных в базовую программу ОМС. На химиотерапию выделено 95 млрд. рублей [3].

K 1 апреля 2020 г. в регионы поступила сумма в размере 63,5 млрд. рублей, что также включает лекарственную терапию 46,6 млрд. рублей. К данному периоду всего проведено 690 тысяч случаев лечения в условиях стационара (круглосуточного и дневного), в том числе на 470 тысяч курсов противоопухолевой лекарственной терапии.

За первый квартал 2020 г. доля злокачественных новообразований, выявленных на 1-2 стадиях, уменьшилась на 0,5\% и составила 57,6\%. По нацпроекту ожидается показатель в 59\%. Показатель по снижению одногодичной летальности больных со злокачественными образованиями в январе - марте 2020 г. составил $21,1 \%$ (целевой показатель на 2020 г. - 20,2\%).

Смертность от онкологических заболеваний в России среди населения в целом ниже на $13 \%$, 
чем «новых» странах Европейского союза (Чехия, Словения, Словакия, Польша и другие), однако выше, чем в «старых» странах Европейского союза и Белоруссии на $11 \%$. Если анализировать смертность от онкологических заболеваний больных в возрасте 0-64 года, то в данной возрастной категории смертность по причине злокачественных новообразований в РФ снизилась на 30\% в период с 1990 по 2020 гг.

Согласно проведенным исследованиям, первичная заболеваемость по онкологической нозологии в РФ ниже на 22\%, чем в восьмерке «новых» стран, и ниже на 28\%, чем в «старых» странах ЕС. Однако, это не свидетельствует о том, что в России меньше болеют злокачественными новообразованиями. Низкие показатели заболеваемость являются свидетельством недостаточно эффективной диагностики онкологических заболеваний, в особенности на ранних стадиях развития заболевания [2].

Стоимость лечения пациентов в России и в развитых странах разнится в достаточно широком диапазоне. Лечение одного онкологического больного в США обходится примерно в 90 тыс. долларов. В России на лечение такого же больного со злокачественным новообразованием отводится около 900 тыс. руб. В перерасчете на доллары это составляет около 12 тыс. долларов (1 доллар США = 75 рублей). Это говорит о том, что в России тратится на лечение и диагностику одного онкологического пациента в 7 раз меньше средств, чем в США.

Также значительно отстает обеспечение лекарственными препаратами онкологических больных в России, в сравнении с экономически развитыми странами. К примеру, во Франции на лекарственное обеспечение онкологических больных тратится в 3 раза больше средств, чем в России, а в США расходуется в 7,5 раз больше средств.

Согласно новым реформам ОМС, снизилось финансирование дорогостоящих химиопрепаратов, исключенных по новому закону из перечня жизненно важных. Так, на 75\% снизились закупки таких дорогостоящих препаратов торизела и жаврола, применяемых для лечения рака мочевого пузыря и почек. Также на 70\% снизились закупки абраксана для лечения рака поджелудочной железы. За счет этих изменений многие больные потеряли шансы на выздоровление и лечение, так как приобрести за свой счет такие дорогие препараты не многие могут себе позволить.

Общее число закупок противораковых хи- миопрепаратов, не включенных в перечень жизненно важных лекарственных средств, снизилось в первом полугодии 2021 г. на 67\%, в сравнении с закупками таких же препаратов в первом полугодии 2020 г. В первом полугодии 2020 г. было потрачено на закупки лекарственных средств почти 2 млрд. рублей, в аналогичном периоде 2021 г. затраты на приобретение химиопрепаратов составили 647,4 млн. рублей. Такие перемены, однако, привели к повышению спроса на препараты в коммерческих аптеках, чьи продажи увеличились на 75\%.

На оплату лекарственных средств, не включенных в перечень жизненно важных, из средств ОМС выделяется только 14 тыс. рублей, чего катастрофически мало, так как стоимость противораковых химиопрепаратов зачастую исчисляется сотнями тысяч. Так, лечение винфлунином обходится больным в 130 тыс. рублей, абраксаном - 200-250 тыс. рублей. Эти цены без учета того, что активно продолжается повышение цен на лекарственные препараты, связанные с падением курса рубля. Первое полугодие 2021 г привело к повышению цен на лекарственные препараты почти на 8\% [6].

В 2016 г. американцы в США тратили 21165976 долларов, не считая ту сумму, которая выплачивалась за лечение по страховке. Помимо общепринятых страховых программ, в Америке широко распространены специальные полиса от онкологических заболеваний, появившиеся здесь впервые в 1950-х гг., за счет которых могут покрываться не только затраты на терапию рака, но и расходы, связанные с временной нетрудоспособностью, проживанием, размещением ребенка в садике на период лечения и другие виды финансовых трудностей пациента.

Цена страхового полиса зависит от возможного объема выплат, а также от возраста больного. Средний размер страховой выплаты 240-380 долларов в год, максимальный размер для одного онкологического больного составляет 1000030000 долларов на одного больного.

Специальные страховые полиса широко распространены и практикуются и в других странах. В Японии такие страховые полиса появились еще в 1974 г. благодаря деятельности американской страховой компании Aflac. В Китае онкологические страховые полиса появились в 2000-х гг. благодаря деятельности западных фармацевтической индустрии.

В России онкострахование зародилось только в 2010-м г., только появилось оно не в целях 
компенсации лечения, а для получения так называемого «второго мнения». Благодаря внедрению системы онкострахования больной получает возможность перепроверки своего диагноза и лечения другим врачом. Примечателен тот факт, что 9\% патологоанатомических диагнозов не совпадает с прижизненными диагнозами. Путем применения современных возможностей телемедицины, пациенты могут проконсультироваться даже с иностранными врачами для уточнения диагноза и коррекции схемы лечения.

Дополнительное онкострахование в России также помогает решить вопрос с получением квоты в тех случаях, когда больному необходимы высокотехнологичные вмешательства и дорогие операции. Для получения таких квот больным зачастую требуется много времени, которого у них катастрофически мало. Даже если квота получена, стоимость квоты может быть не достаточна для полного покрытия стоимости лечения [4].

Еще одной важной особенностью онкологической службы в России является территориальный принцип диагностики и лечения. В настоящее время пациенты, согласно ФЗ № 323 «Об охране здоровья граждан», могут выбирать, к какому лечебному учреждению прикрепиться, независимо от прописки. В соответствии с современными реформами, вступающими в силу с 1 января 2022 г., больные смогут получать бесплатное обследование и лечение только по месту прописки.

В регионах нет достаточного оснащения для полноценной диагностики заболеваний, нет зачастую нужных специалистов, в результате чего значительно снижаются качество диагностики и лечения больных. Определять, требуется ли больному то или иное лечение за пределами территории прописки, будет специально назначенная для этого комиссия. Только каким образом будет назначаться эта комиссия и кто будет в ее состав входить, пока неизвестно.

Все реформы, проводимые в сфере онкологической службы, проводятся с целью повышения возможностей выявления рака на более ранних стадиях, а также понижения смертности населения от заболеваний данной категории. С экономической точки зрения лечение больных раком на более ранних стадиях более выгодно. Так, лечение рака молочной железы I стадии в 15-30 раз дешевле, чем лечение рака на III стадии. Выявление рака на ранней стадии повышает также возможности пациента на выздоровление [5].
Рак молочной железы является основной причиной смертности женщин трудоспособного возраста, в связи с чем необходимо проводить мероприятия по как можно более ранней диагностике и профилактике данного заболевания. Мероприятия по ранней диагностике рака молочной железы сводятся к «Золотому стандарту» обследований для выявления рака молочной железы, включающему в себя выполнение лабораторного исследования на онкомаркеры, хромосомные исследования «генов карциномы груди» (BRCA-1 и\или BRCA-2), ультразвуковое исследование, маммографию. Также, при необходимости, для уточнения диагноза проводятся MPТ, фиброоптическая дуктоскопия, лапароскопическая миниинвазивная биопсия с гистологией полученной ткани, а также радионуклидная диагностика. Проведение такого комплекса исследований рекомендовано всем женщинам после 50 лет 1 раз в 2 года, что повышает шансы диагностики карциномы груди на ранних стадиях, когда лечение ее гораздо эффективнее [7].

Скрининговая маммография проводится во всех странах женщинам в возрасте 50-70 лет. Среди женщин из группы риска (с семейным раком молочной железы или наличием мутации генов) проводится в возрасте старше 40 лет. В более молодом возрасте проведение маммографии не рекомендовано, альтернативным методом диагностики для них является УЗИ молочных желез [6].

Для стимулирования больных к своевременным обследованиям на уровне государства внедряются различные меры поощрения. В частности, в России предложено снизить подоходный налог для лиц, регулярно проходящих диспансеризацию. Подобные мероприятия по поощрению тех, кто регулярно проходит медицинские осмотры, в Германии, США и других развитых странах практикуются давно.

Таким образом, проведенная исследовательская работа показывает слабые стороны системы здравоохранения, которые нуждаются в доработке и изменениях. Лечение зачастую обходится дорого, а методы обследования и лечения доступны только в централизованных клиниках страны. На лечение и диагностику онкологических заболеваний ежегодно выделяются денежные средства, однако, многие вопросы все еще остаются нерешенными и требуют доработки, в частности, доступность дорогостоящих лекарственных препаратов. 


\section{Библиографический список}

1. Приказ Минздрава России (Министерство здравоохранения РФ) от 19 февраля 2021 г. № 116 «Об утверждении Порядка оказания медицинской помощи взрослому населению при онкологических заболеваниях»;

2. Александрова Л. М., Калинина А.М., Ипатов П.В., Грецова О.П., Старинский В.В., Каприн А.Д., Бойцов С.А. Выявление рака молочной железы: состояние проблемы, пути решения. Онкология. Журнал им. П.А. Герцена. 2016; 5 (2).- с. 34-39;

3. Каприн А. Д., Александрова Л. М., Старинский В. В., Мамонтов А. С. Технологии диагностики и скрининга в раннем выявлении злокачественных новообразований. Онкология. Журнал им. П.А. Герцена. $2018 ; 7$ (1).c. 34-40;

4. Пинхосевич Е.Г., Легков А. А., Бурдина Л. М. Этапы создания маммологической службы в г. Москве и пути ее дальнейшего развития// Актуальные проблемы маммологии.-Москва.-2017.-с.5-13;

5. Рожкова Н.И. Современное состояние маммологической службы в Российской Федерации// Актуальные вопросы маммологиию-Москва.-2017.-с. 13-22;

6. Доклад американской ассоциации по изучению рака о прогрессе в онкологии. / [Электронный ресурс] / / URL: https://www.rakfond.org/;

7. Интернет-портал российского сообщества клинической онкологии / VI Российская онкологическая конференция / / [Электронный ресурс] / / URL: https://rosoncoweb.ru/library/congress/ru/06/09.php. 